\title{
The church and the indispensability and fragility of morality revealed by the COVID-19 pandemic
}

\begin{abstract}
Author:
D. Etienne de Villiers ${ }^{1}$ (D)

Affiliation:

${ }^{1}$ Department of Systematic

Theology and Church History, Faculty of Theology,

University of Pretoria,

Pretoria, South Africa

Research Project Registration: Project leader: D.E. de Villiers Project number: 2460084

Description:

Prof. Etienne de Villiers is an emeritus-professor of the Department of Dogmatics and Christian Ethics, Faculty of Theology, University of Pretoria. This research is part of his research on 'Christian Ethics'.
\end{abstract}

\section{Corresponding author:}

Etienne de Villiers,

etienne.devilliers@up.ac.za

Dates:

Received: 01 June 2020 Accepted: 26 Aug. 2020

Published: 03 Nov. 2020

How to cite this article: De Villiers, D.E., 2020,

'The church and the indispensability and fragility of morality revealed by the COVID-19 pandemic', HTS Teologiese Studies/Theological Studies 76(1), a6180. https:// doi.org/10.4102/hts.

v76i1.6180

\section{Copyright:}

C 2020. The Authors. Licensee: AOSIS. This work

is licensed under the

Creative Commons

Attribution License.

\section{Read online:}

Scan this $Q R$ code with your smart phone or mobile device to read online.
In this article the view that the Covid-19 pandemic - especially the lockdown that went hand in hand with it - revealed both the indispensability and fragility of morality was substantiated and the response of the church to the moral challenges posed by the pandemic discussed. Findings were based on information gained from South African media regarding the pandemic and the response to it in the South African context interpreted with the assistance of research in academic publications. Various respects in which the pandemic underlined the indispensability of morality were discussed first. This was followed by a discussion of ways in which the pandemic also demonstrated the fragility of morality. The fragility of morality was traced back to the undermining influence of modern life on morality. Finally, the mixed record of South African churches in providing guidance on the moral challenges the Covid-19 pandemic posed, was noted. It was pointed out that the challenge remains to the church to provide moral guidance on life after the pandemic. The church would also have to effectively deal with the challenge to overcome the curtailment of its ability to provide such moral guidance in contemporary modern societies.

Contribution: The contribution of the article lies in identifying the moral issues posed by the Covid-19 pandemic and in gauging the response of the church in the South African context to these issues. The challenges that remain to the church to also after the pandemic provide moral guidance and overcome obstacles in providing such guidance were also highlighted.

Keywords: alternative lifestyle; church; COVID-19 pandemic; economic inequality; fragility of morality; flourishing; indispensability of morality; modern culture; morality.

\section{Introduction}

Since the outbreak of the COVID-19 pandemic we have been confronted in the media with a variety of scenarios of a completely different life that awaits us after the termination of the pandemic. ${ }^{1}$ One of the more impressive of these scenarios is presented in a video called 'The Great Realisation', distributed via WhatsApp. The video visualises a situation, somewhere in the future, of a father reading to his son at bedtime the real-life story of the far-reaching realisation that dawned on humankind during the COVID-19 pandemic in 2020 that life could be lived differently and less destructively. In the story a vivid sketch of the frenetic pace of life before the outbreak of the pandemic going hand in hand with exponential economic growth and rapid technological development is first provided. The inevitable result was the depletion of natural resources, air and water pollution, extreme economic inequality and unhealthy lifestyles. The story relates how people during the lockdown, as a result of the pandemic, learned to be more friendly, caring and thankful to other people, started to exercise more and developed artistic and practical sides of their personality hitherto neglected. They could also experience that the skies grew clearer and wildlife thrived as a result of the curtailment of industrial activities. The punchline comes near the end of the story when the male presenter concludes:

So when we found a cure and were allowed to go outside, we all preferred the world we found to the one we left behind. Old habits became extinct and they made way for the new. And every simple act of kindness was now given its due.

One could argue that the video, through its vision of an alternative way of living in the aftermath of the pandemic, underlines the importance, even indispensability, of living a morally responsible life. Indeed - and this I would like to confirm in this article - especially the lockdown that went hand in hand with the COVID-19 pandemic - at least as experienced in South Africa - taught us that life is not worth living if it is not lived in accordance with the guidelines of morality. This is

1.Li Edelkoort, an expert on trends, for example, predicted that as a result of the COV undertaken on a much more minimalist scale (reported by Alet Wichman, in an article In Rapport Beleef, 12 April 2020). 
something we have to a large extent forgotten in modern life. For this forgetfulness contemporary modern culture is partly to be blamed. Modern life is all but supportive of morality. In fact, as I would like to point out, modern culture has downplayed, even undermined, morality. That this could happen points to another characteristic of morality I would also like to discuss with reference to the COVID-19 pandemic, namely its fragility. This complicates the challenge that the church is faced with, namely to contribute to the establishment of a new, morally desirable lifestyle. The church has to counter the fragility of morality not only in wider society but also in the lives of its own members who are immersed in modern culture, and in its own practices.

\section{The indispensability of morality}

Why should morality be regarded as indispensable? It is true that most people intuitively have some sense of what morality is about and of its central importance in life. To arrive at a convincing answer, we, however, have to do better than to fall back on vague intuitions. A good starting point in our effort to get more clarity on morality is, in my opinion, to identify it as the social institution that has taken shape in human history to provide an answer to one of the most fundamental questions in life: 'How ought I/we to live'? This question has, for the most part, been understood comprehensively: 'How ought we to live in order to flourish personally and communally?'2 To accommodate the different answers given to this question in history, we likewise require a comprehensive understanding of 'flourishing' as including not only physical, psychological and social well-being but also spiritual fulfilment. ${ }^{3}$ Morality, whether as part of a religion or a philosophy of life, or as a separate social institution, has served the purpose of answering this question by providing normative orientation to human conduct. It has identified the normative notions most important in striving to achieve human flourishing: the major goals we should direct our actions to, the cardinal virtues we should instil to shape our inclinations to act in acceptable ways and the fundamental prescriptions we should follow when deciding on the right actions in concrete situations. ${ }^{4}$

The indispensability of morality, understood in this manner, is indisputable. To deny its indispensability in life would be to deny the importance of human flourishing in the comprehensive sense of the word. No wonder that very few dared to theoretically dispute the need to live a morally responsible life (cf. Bayertz 2004:27). This does not take away

2.Aristotle already in his Nicomachean ethics identified 'eudaimonia' as the goal of morality. According to Gerald J. Hughes, Aristotle did not understand 'eudaimonia' as 'feeling of happiness', but rather as 'fulfilment' or 'living a worthwhile life' (Hughes 2001:22-23). Kenan Malik is of the opinion that 'eudaimonia' could best be translated as 'human flourishing' (Malik 2014: 34).

3.Viroslav Volf claims that the emphasis on comprehensive flourishing is found in all world religions: 'World religions distinguish between the transcendent and mundane realms and give priority to the former; they are concerned with the good that goes beyond ordinary flourishing and contend that attachment to the transcendent realm is in fact the key to ordinary flourishing' (Volf 2015:44).

4.I developed my views on a definition of morality that would be acceptable for people from different cultures, religions and views of life more extensively in my monograph Revisiting Max Weber's ethic of responsibility (De Villiers 2018:203-206), and in the article 'An ethics of responsibility for our time: proposal' (De Villiers 2020a:163-184). that people often do live immoral lives. And it also does not take away that human beings can become so obsessed by other than moral priorities that moral considerations are sidelined, or simply forgotten. That modern life has, until the outbreak of the COVID-19 pandemic, suffered from a certain moral amnesia is something that could hardly be denied.

The outbreak of the COVID-19 pandemic shocked many of us out of our moral amnesia and reminded us of the indispensability of morality. And it did this in different ways. First of all, it confronted us with medical guidelines and government regulations with a clear moral purpose. It is true that one of the purposes of the guidelines to wash hands regularly, to maintain social distancing and to wear a mask when going outside is to minimise the chances of becoming infected. The guidelines, however, also have the purpose of preventing the spread of infection to other people. As Andrew M. Cuomo, the governor of the New York State, put it in one of his regular press conferences televised on Cable News Network (CNN): 'I wear a mask to protect you!' A person showing no symptoms of infection might nevertheless be in the incubation phase of infection or might be one of those people who are infected in an asymptomatic way. Whilst lockdown regulations involved the curtailment of many of the freedoms we had become used to in liberal democracies and were in many respects bothersome for us to adhere to, some crisis situations present moral reasons for being willing to make such sacrifices. This is when 'turning in' some of our individual rights and freedoms is necessary to serve a bigger purpose, to serve the common good. ${ }^{5}$ The COVID-19 pandemic is undoubtedly such a crisis situation.

Secondly, the COVID-19 pandemic presented people with often uncomfortable and difficult moral questions. Being at home with their families as a result of the lockdown, people who normally work away from home were confronted by the question of the fair distribution of household chores amongst family members. More difficult was the question of how to serve the best interests of elderly parents during the lockdown. As medical experts made it clear that elderly people are more prone to become seriously ill and die when they are infected, children realised that it would be best to not visit their elderly parents in person to avoid exposing them to the risk of infection. However, by doing so, they inevitably contributed to the social isolation of their parents. Many employers wrestled during the lockdown with the difficult question of whether to continue paying wages to absent employees, or rather dismiss them or temporarily suspend the payment of wages, thereby increasing the firm's chances of survival whilst causing extreme financial hardship to their employees. What increasingly became evident was that the lockdown significantly aggravated the suffering of poor people and other vulnerable people in countries like South Africa characterised by extreme economic inequality.

5.Danny Titus in an interview with Carla Lewis in the paper Beeld of 15 May, 2020 allured to this willingness. He detected willingness to 'turn in' individual rights and freedoms for the greater good among Dutch people (they use the Dutch word 'inleveren') but was not of the opinion that such willingness could be found among 'inleveren') but was not
many South Africans. 
Like never before privileged people in South Africa were not only confronted with the question: 'What are you personally doing to alleviate the suffering of poor and hungry people?' but also with the more uncomfortable one: 'Do you accept that the present extreme economic inequality is totally unacceptable from a moral perspective and that its eradication should be the number one priority in our society?' As the financial hardship the strict lockdown measures were causing increasingly became apparent, the moral dilemma that the South African government had been confronted with from the start only deepened:

Should strict lockdown measures be retained to restrict the number of deaths as a result of COVID-19 infection, but at the increased risk of the financial ruin of many businesses and personal financial hardship? Or, should the lockdown measures be relieved to allow the economy to open up and people to go back to work, but at the risk of the exponential increase of COVID-19 infections and deaths?

As Alex Broadbent pointed out, this moral dilemma was not so much one in which a choice was to be made between lives and financial hardship, but more accurately between lives and lives, the lives of predominantly elderly people who would die as a result of COVID-19 infection and the lives of predominantly young children who would die as a result of hunger and illnesses like measles and tuberculosis on account of weakened immune systems (in an interview with Carla Lewis in Beeld, 17 April 2020).

Thirdly, the COVID-19 pandemic on a large scale elicited morally commendable behaviour from us. One of the most uplifting experiences during the lockdown was to witness how many people without hesitation stepped up to do what is morally required of them. Many, especially health workers, heroically risked their own safety to save the lives of others. For this they were awarded in many countries with public outpourings of thankfulness. Others went to lengths to buy and deliver food for elderly and sick people living in their neighbourhood on a regular basis. Children made innovative plans by using electronic media to regularly communicate with elderly parents they were unable to visit. Working people were, for the most part, willing to do their share at home and to improve their communication with their spouses and children. Musicians and other artists in creative ways entertained people from their balconies, in the street and on electronic platforms and in this way helped to soften the isolation and recreate some sense of community. And when the government and welfare organisations called for donations to alleviate the plight of poor people, the response was overwhelming.

Fourthly, the COVID-19 pandemic invited us to rethink our priorities in life and to consider living more morally responsible lives in future. Besides having more time to think, people could get the taste of a different lifestyle involving more personal interaction with family members, attention to neglected cultural interests and often more exercise. In addition many discovered to their surprise that they did not miss their previous lavish lifestyles and that the benefit of not spending money on luxury goods, restaurants and travelling was that they could manage with their income and even had more money in the pocket. ${ }^{6}$ Being confronted with the need of their employees and the many desperately poor people in society, and having experienced that they care about them, especially more privileged people also felt obliged to think about what they in future might do in this regard. Questions they had to face were: 'What should I personally do to help people?' and 'What would be the most effective channels I should make use of $?^{\prime 7}$ Those who came to realise that overcoming the extreme economic inequality in society should be the number one priority of the government, businesses and non-governmental organisation (NGOs) were faced with the difficult task of deciding which government policies to promote and which political party and NGOs to support. Finally, having experienced how the skies grew clearer and how wildlife thrived during the lockdown as a result of reduced production and travelling, many realised that it is possible to turn around the ecological devastation and that they also had a personal obligation to commit themselves to the cause of environmental preservation. The challenge they have been faced with since then is to turn this realisation into practical application.

\section{The fragility of morality}

There is, however, also a flip side when it comes to morality during the COVID-19 pandemic. The pandemic demonstrated not only the indispensability but also the fragility of morality. It showed that morality can easily be trampled on by people, and can in some extreme situations be difficult, if not impossible to uphold.

From the start of the lockdown there were people who refused to 'turn in' some of their freedoms and, sometimes even recklessly, ignored the safety guidelines prescribed by medical experts and government. There were also those who saw in the lockdown period an opportunity to further their own interests through criminal activities. South African media reported several cases of municipal counsellors who appropriated food parcels destined for distribution amongst poor and hungry people. Others robbed money of poor people after they had collected their monthly government subsidies at cash points, or looted food shops and bottle stores. Still others took advantage of the government ban on tobacco sales to expand their illegal trade of tobacco products. Corruption also raised its ugly head when certain officials in the national and provincial governments secured government contracts for personal protective equipment (PPEs), for companies owned by family members. Those prone to using inflammatory language on social media increased the intensity of their

6.Annemarie van der Walt writes in a column (Van Alle Kante, Beeld, 21 May 2020) that she during the lockdown met a young mother with children in a supermarket that she during the lockdown met a young mother with children in a supermarket who enthusiastically told her that she was considering not going back to work, as spending time with the children is priceless.

7.Peter Singer stresses the importance of not only disciplining yourself to have money Peter Singer stresses the importance of not only disciplining yourself to have money
available to sponsor morally commendable causes but to also ascertain which available to sponsor morally commendable causes but to also ascertain which
organisations would most effectively serve these causes, before donating (Singer organisations woul 
condemnatory and racist remarks in criticising, amongst others, government lockdown regulations. Some police and army members could not refrain from misusing their expanded authority to mishandle civilians who allegedly transgressed lockdown regulations. The lockdown also led to a substantial increase in the mistreatment of women and children in households. During the first 3 weeks of the lockdown, the gender-violence call centre of the South African government received more than 120000 calls from victims, twice the number usually received during such a period (reported in Beeld, 18 May 2020). Dirk Jordaan rightly asserts in a column in Beeld (09 May 2020) that in crisis times like these inherent character traits and inclinations of people do not change. With reference to Charles Dickens' A tale of two cities, he concludes that the COVID-19 pandemic appears to have brought out the best in some people, but the worst in others.

What the lockdown clearly demonstrated is that the capacity of people to uphold restrictive measures with a moral purpose tends to weaken over time. Even people who at the beginning of the lockdown period diligently adhered to the lockdown regulations protested when the South African government, after a 5-week period of strict (the so-called level 5) measures, decided to expand the lockdown period with somewhat less restrictive (the so-called level 4) measures. One reason was that people after 5 weeks of almost total social isolation longed to move around more freely, again socialise with family and friends, resume sport activities, attend church services and return to work and see their colleagues. However, the main reason was not unfulfilled social needs, but mounting economic anxieties. After such a long period of almost total shutdown of the economy, and with more and more people receiving no income, the financial situation of many became desperate. For those in such a desperate situation it became more and more difficult to persistently observe the lockdown regulations. Visual reports of hungry people streaming in their thousands to distribution points for food parcels without maintaining social distancing and sometimes also pushing and shoving to get hold of a food parcel demonstrated this in quite a dramatic manner. The choice for these people was not, anymore, a simple one between morally responsible behaviour (obeying regulations to save lives) and morally irresponsible behaviour (risking the lives of people by disobeying the regulations), but between compliance and survival.

The fragility of morally responsible behaviour during the lockdown period was exacerbated in the South African society by the mutual reinforcement of two crises: the COVID-19 pandemic and the existing extreme economic inequality. The COVID-19 pandemic aggravated the dire financial situation of those on the wrong side of the economic divide, whilst in turn the desperate economic situation of such people made it difficult, if not impossible, for them to heed calls for morally responsible behaviour. This demonstrates, from a more general vantage point, the highly problematic nature of the view of some political analysts that the dire economic and morally unstable situation of poor people is to be solely blamed on their own lack of personal responsibility. ${ }^{8}$ As the American philosopher Iris Marion Young rightly points out in her book Responsibility for Justice, although it is true that all individuals should take personal responsibility for their lives, for the improvement of their own financial and social situation, and for acting morally responsibly, the crucial role of unjust economic and social structures in making it difficult for them to do so should also be taken into account (Young 2011:3-41). Those who expect people to always act in a morally responsible manner should thus be champions not only for taking personal responsibility but also for taking collective political responsibility for eradicating unjust economic and social structures.

The extreme economic inequality that contributed to the economic, social and also moral vulnerability of poor people during the lockdown period is, of course, something that already characterised modern life before the outbreak of the COVID-19 pandemic. Many factors contributed to this extreme economic inequality. Undeniably, one of the contributing factors has been the dominance of the so-called neoliberal capitalism in the world economy since the eighties of the previous century. Proponents of neoliberal capitalism accept not only the old laissez-faire idea that politicians should leave the market and business alone but also that selfishness as the natural, dominant determinant of human behaviour should guide economic activity. Rising economic inequality is accepted as inevitable and social justice rejected as a moral guideline for the economy (cf. Aldred 2019:6-13). This is not the only way in which the modern economy undermines the recognition of moral considerations. According to Zygmunt Bauman, the dominant consumer culture in our globalised world has in many respects contributed to a widespread moral blindness or loss of moral sensitivity (Bauman 2009:59; Bauman \& Donskis 2013). And it is not only the modern economy that has an undermining impact on morality, but other aspects of modern life also have such an impact: the influence of political realism in modern politics, scientism in modern science and technicism in modern technology (cf. De Villiers 2018:166-170; 187189). Where in pre-modern societies one dominant set of moral values mostly provided moral orientation to everyone, modern contemporary societies are for the most part characterised by a bewildering pluralisation of moral values (cf. Berger 2014; Taylor 2007:473-504). The COVID-19 pandemic thus only underscores the fragility of morality that is part and parcel of modern life.

\section{The challenge to the church}

There is a certain irony when it comes to the role of the church during the lockdown. On the one hand, the lockdown offered to the church the ideal opportunity to play a prominent role in society. The financial suffering many

8.Especially during the eighties of the previous century, the view of a number of political analysts that the causes of being poor are largely traceable to attributes and behaviour of the poor themselves, spread quickly among liberals, as well as conservatives (cf. Young 2011:3) 
people experienced during the lockdown created the need for the church to mobilise its members in providing effective relief. There was the need to provide guidance on difficult moral issues that cropped up: amongst others, safeguarding one's own financial security as employer versus preventing the financial hardship of employees by keeping them employed, and curtailing the spread of COVID-19 infection by strict lockdown measures versus lifting the restrictions to allow people in all walks of life to earn a living. There was also the need to provide moral guidance on a more balanced and moderate lifestyle that has a less negative impact on personal well-being, personal relationships and the environment. And lastly, there was the need not only for a prophetic voice against government officials resorting to theft and corruption and the government's neglect of the economic needs of poor people, but also for a prophetic call to all relevant role players to prioritise the elimination of the extreme economic inequality, without at the same time neglecting the preservation of the natural environment in South Africa. On the other hand, the lockdown undoubtedly reduced this opportunity to play a prominent role on account of the restrictions on church services and other church meetings.

In spite of these restrictions, the lockdown did not prevent individual church members, congregations and Christian welfare organisations from providing care to people in need on a large scale. Nelis Niemand in an article published in Beeld during the time of the lockdown concludes: 'Millions of church members are involved in feeding-schemes, aid campaigns, old age homes and orphanages' (Beeld, 19 May, 2020; translated from the Afrikaans). In addition, congregations in innovative ways created channels of communication to provide spiritual guidance to church members by means of online sermons and online pastoral care. Whilst recognising the valuable contribution of church members, congregations and Christian welfare organisations, Niemand is nonetheless critical of theologians and church leaders for not optimally utilising the opportunity to provide guidance on moral issues people were confronted with during the lockdown. They were, in his opinion, 'for the most part silent in the big public discussions on the pandemic' (Beeld, 19 May 2020; translated from the Afrikaans). It is at this stage not possible to make a final assessment of the accuracy of Niemand's conclusion as no relevant information based on thorough research is available. However, my personal impression is that theologians and church leaders were indeed not very vocal in providing moral guidance on media platforms and in inspiring them with a moral vision of a better South African society. ${ }^{9}$

Why was this the case? A variety of contributing factors could be mentioned. I would, however, like to highlight three contributing factors that are part and parcel of contemporary modern life. The first is the separation of

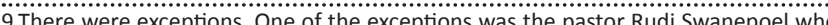
called for a 'deep social transformation' in South Africa and globally. Such transformation involves in his view the 'giving' of oneself to another person, of transformation involves in his view the 'giving' of oneself to another person, of
one's own group to another group, bridging differences and a difficult history (Beeld My Naweek, 09 May 2020). church and state that is characteristic of liberal democracy but was introduced in South Africa only with the new political dispensation in 1994. The new constitution does not allow the government to favour a particular religion or base its policies on religious values. This resulted in great uncertainty on the acceptability for churches of taking part in public debates on ethical issues and government policies on the basis of distinctive Christian moral values. This is an uncertainty that has never been fully overcome. Church representatives are, therefore, often hesitant to take part in public discussions on ethical and policy issues. A second factor is the negative impact that the accelerated secularisation since 1994 has had on, especially mainline, South African churches. The introduction of the new political dispensation finally broke down the cultural isolation during the previous political dispensation, at the same time opening flood gates to secularising influences. The loss of membership numbers and income often led to a survival-mode and the pre-occupation with projects that could secure the institutional survival of one's own denomination or congregation. This in turn contributed to a certain church-centredness and a lack of attention to burning ethical issues in broader society. A third factor is the pluralisation of ethical views in South African churches. Especially after the Second World War, modernisation processes have had a strong individuating effect in the Western world, meaning that individuals have increasingly adopted their own distinctive lifestyles and sets of beliefs, including moral beliefs (Taylor 2007:473). Amongst others, the result has been a dramatic increase in the plurality of moral views held by Christians, even amongst those who are members of the same church. Especially during the last two decades, the pluralising impact of modernisation on the moral stances of Christians could also be clearly detected in South Africa. This, of course, created challenges for churches. It is difficult to provide meaningful guidance on ethical matters, even more so on ethical issues in society, without annoying at least some members. The temptation is, therefore, to avoid giving any guidance on such matters. One could say that these three factors have contributed to what Peter Berger calls the 'fragilisation' of the Christian ethical message in the South African context (Berger 2014:9). ${ }^{10}$

The church is thus faced at this point in time with a twopronged challenge. First of all, some of the serious moral questions raised by the lockdown still remain with us and would have to be dealt with by the church. These moral questions could be subdivided in three broad categories: (1) those concerning the lifestyle we ought to follow in future, (2) those concerning our attitudes and actions over against fellow human beings, especially those in need, as well as over against the natural environment and (3) those concerning the just and environmentally friendly society we should strive to

10.In this paragraph I incorporate views that I developed in my article "Does the Christian church have any guidance to offer in solving the global problems we are faced with?' (De Villiers 2020b:a5852) 
establish in South Africa, and globally. In reflecting on the moral guidance that should be provided, the church could draw on Christian ethical reflection stretching over two millennia, inter alia on a moderate lifestyle, charity over against those in need, justice and peace in society and care for the natural environment. Secondly, in order to provide meaningful guidance on these moral questions, the church would have to find ways to overcome the curtailment of its own ability to provide such guidance. Should the church fail to do so, it would not only be unfaithful to its own mission but would also be experienced by contemporary people as irrelevant when it comes to contributing to the solution of the serious moral problems of our time.

\section{Conclusion}

That the COVID-19 pandemic, and especially the lockdown, underscored both the indispensability and fragility of morality has been demonstrated in this article. The contribution of modern life to the fragility of morality should, however, not be left out of the equation. The renewed awareness of the indispensability of morality during the COVID-19 pandemic has provided the church with the opportunity to provide moral guidance on an alternative lifestyle, renewed relationships to fellow human beings and the natural environment and a better society. The church, at the same time, also has to deal with the curtailment of its ability to provide such moral guidance in contemporary modern societies.

\section{Acknowledgements}

\section{Competing interests}

The author declares that he has no financial or personal relationship which may have inappropriately influenced him in writing this article.

\section{Author's contributions}

D.E.d.V. is the sole author of this article.

\section{Ethical consideration}

The author confirms that ethical clearance was not needed or required for the study.

\section{Funding information}

The research received no specific grant from any funding agency in the public, commercial or not-for-profit sectors.

\section{Data availability statement}

Data sharing is not applicable to this article as no new data were created or analysed in this study.

\section{Disclaimer}

The views and opinions expressed in this article are those of the author and do not necessarily reflect the official policy or position of any affiliated agency of the author.

\section{References}

Aldred, J., 2019, Licence to be bad: How economics corrupted us, Allen Lane, London.

Bauman, Z., 2009, Does ethics have a chance in a world of consumers?, Harvard University Press, Cambridge, MA.

Bauman, Z. \& Donskis, L., 2013, Moral blindness: The loss of sensitivity in liquid modernity, Polity, Cambridge.

Bayertz, K., 2004, Warum überhaupt moralisch sein?, C.H. Beck, Munich.

Berger, P., 2014, The many altars of modernity: Toward a paradigm for religion in a pluralist age, Walter de Gruyter, Boston, MA.

De Villiers, E., 2018, Revisiting Max Weber's ethic of responsibility, Mohr Siebeck, Tübingen.

De Villiers, E., 2020a, 'An ethics of responsibility for our time: A proposal', Stellenbosch Theological Journal 6(1), 163-184. https://doi.org/10.17570/stj.2020.v6n1.a10

De Villiers, E., 2020b, 'Does the Christian church have any guidance to offer in solvin the global problems we are faced with?', HTS Theological Studies 76(2), a5852. https://doi.org/10.4102/hts.v76i2.5852

Hughes, G.J., 2001. Aristotle on ethics (Routledge philosophy guidebook), Routledge, London.

Malik, K., 2014, The quest for a moral compass: A global history of ethics, Atlantic Books, London.

Singer, P., 2015, The most good you can do: How effective altruism is changing ideas about living ethically, Yale University Press, New Haven, CT.

Taylor, C., 2007, A secular age, The Belknap Press of Harvard University Press, Cambridge, MA.

Volf, M., 2015, Flourishing: Why we need religion in a globalised world, Yale University Press, New Haven.

Young, I.M., 2011, Responsibility for justice, Oxford University Press, New York, NY. 